\title{
REDACTIONEEL
}

\section{Mediation/bemiddeling in de rechtspraak binnen Europa}

\author{
Annie de Roo \& Rob Jagtenberg
}

Er zijn de afgelopen jaren nogal wat boeken en artikelen gepubliceerd waarin ontwikkelingen op het gebied van mediation/bemiddeling vanuit een vergelijkend Europees perspectief werden geanalyseerd. Dat is ook begrijpelijk, gezien de voortrekkersrol die de Europese Unie en de Raad van Europa op dit gebied gedurende langere tijd hebben gespeeld. ${ }^{1}$

Zonder ook maar enige aanspraak op volledigheid te maken, kan gewezen worden op de recente Europese/internationale naslagwerken die over mediation en ADR in het algemeen zijn verschenen onder redactie van Steffek en collega's, van Espugles Mota en collega's, van Brenneur en GEMME, en van Schonewille en Schonewille. $^{2}$ Eerdere vergelijkende studies werden uitgebracht door onder andere Martin-Casals en collega's, door CEDR, door Alexander, en door Cadiet en collega's. ${ }^{3}$ Nog eerder zelfs, in de jaren tachtig, zijn al aanzetten gegeven tot vergelijking van ADR-figuren door Blankenburg en Taniguchi, en door Kötz en Ottenhof. ${ }^{4}$ Deze belangrijke studies hebben de contouren van het moderne mediationlandschap (en vaak ook de procesrechtelijke omgeving, voor zover relevant) in kaart gebracht. Daarbij ging begrijpelijkerwijze de aandacht vooral uit naar het aspect van regulering - door bijvoorbeeld wetgeving of gedragscodes - en naar achterliggende politieke discussies en beleidsstukken.

Cijfers over het daadwerkelijk gebruik van mediation komt men soms ook in deze studies tegen, maar niet overal is het empirisch onderzoek even vergevorderd.

1 Zie voor een reconstructie over de periode 1976-2016 o.a. A. de Roo en R. Jagtenberg (2016), 40 jaar Europa en Mediation, TMD 20(3), p. 19-38.

2 F. Steffek, H. Unberath, H. Genn, R. Greger and C. Menkel-Meadow (Eds.), Regulating Dispute Resolution, Oxford: Hart Publishing 2013. C. Espugues Mota, J.L. Iglesias Buhigues and G. Palao Moreno (Eds.), Civil and Commercial Mediation in Europe, Antwerp: Intersentia 2014. B. Brenneur (Ed.), Overview of Judicial Mediation in the World, Paris: L'Harmattan 2010. M. Schonewille and F. Schonewille, The Variegated Landscape of Mediation - A comparative Study of Mediation Regulation and Practices in Europe and the World, The Hague: BJU/Eleven 2014.

3 M. Martin Casals and J. Ribot (Eds.), The Role of Self-determination in the Modernisation of Family Law in Europe, ISFL Conference papers, 2003. K. Mackie, T. Hardy and G. Massie, The EU Mediation Atlas, London: CEDR 2004. N. Alexander (Ed.), Global Trends in Mediation, Köln: Centrale für Mediation 2003; later editions of this collection were published by Kluwer Law International. L. Cadiet, T. Clay and E. Jeuland (Eds.), Médiation et Arbitrage - Alternative à la justice ou justice alternative? Perspectives comparatives, Paris: Litec 2005.

4 E. Blankenburg and Y.Taniguchi, Informal Alternatives to and within Formal Procedures, Amsterdam/Utrecht: Reports presented at the 8th International Congress on Procedural Law 1987. H. Kötz and R. Ottenhof, Les Conciliateurs, La Conciliation, une étude comparative, Paris: Economica 1983. 
Dat hebben ondergetekenden destijds ook moeten ervaren, toen zij in opdracht van het Nederlandse ministerie van Justitie empirische gegevens in de buurlanden zochten om op basis daarvan uitspraken te kunnen doen over de effectiviteit van verschillende typen regulering. Onze poging tot meta-analyse van de (destijds) in vijf Europese landen verzamelde data werd met de nodige slagen om de arm gepresenteerd wegens de per land verschillende opzet van dergelijk onderzoek. $^{5}$

\section{Mediation in de rechtspraak}

Men kan ook proberen iets over het gebruik van mediation aan de weet te komen door analyse van rechterlijke uitspraken waarin mediation het hoofdonderwerp vormt. Deze insteek is vooral interessant, omdat dit iets laat zien over hoe regels uitwerken in de praktijk en met name hoe het gesteld is met de standpunten van rechterlijke autoriteiten over mediation. Men moet evenwel rekenen met een behoorlijke 'incubatietijd', dat wil zeggen: de tijd die betrekkelijk nieuwe arrangementen zoals mediation nodig hebben om binnen een rechtssysteem bekendheid te krijgen en gebruikt te worden in conflicten die tot in de rechtszaal worden uitgevochten. Lijkt er voldoende tijd te zijn verstreken om een werkbare hoeveelheid van uitspraken te mogen verwachten, dan nog is er het probleem van de context, de taal en techniciteit van rechterlijke uitspraken die een dergelijke exercitie bemoeilijken.

Toch is ontsluiting van de rechtspraak inzake mediation/bemiddeling van groot belang. U zult als TMD-lezer al spoedig merken hoe zeer de rechtspraak uiteenloopt tussen de in deze aflevering bestreken vijf lidstaten. Wat betekent dat bijvoorbeeld voor de effectiviteit van het harmonisatiestreven van de Europese Unie op dit vlak?

Wil men het debat op Europees niveau verder brengen, dan zal men inzicht moeten hebben in de wijze waarop de rechtspraak in de afzonderlijke lidstaten met mediation omgaat. Daaraan wil TMD met deze aflevering een bijdrage leveren.

Het nu voor $\mathrm{u}$ liggende themanummer over mediation in de rechtspraak van een aantal Europese jurisdicties kon uiteraard slechts tot stand komen dankzij de medewerking van een viertal excellente auteurs, uit Frankrijk: Raadsheer Marc Juston, uit Duitsland: professor Ulla Gläßer, uit het Verenigd Koninkrijk: professor Bryan Clark, en uit Italië: professor Elisabetta Silvestri. Deze auteurs bleken stuk voor stuk ideaal gepositioneerd te zijn om de meest opvallende ontwikkelingen in de rechtspraak in hun respectievelijke jurisdicties in beeld te brengen. De redactie is niet alleen verheugd over de medewerking van betrokkenen, maar spreekt ook meteen haar erkentelijkheid uit aan twee 'oudgedienden' op mediationgebied, professor Felix Steffek, en Madame Béatrice Brenneur, die de redactie na enige omzwervingen in contact hebben gebracht met de uiteindelijke Duitse en Franse auteurs.

5 A. de Roo and R. Jagtenberg, Europese Mediationpraktijken, Den Haag: Boom Juridische uitgevers 2004. 


\section{Opbouw van de bijdragen in dit themanummer}

De artikelen die in dit themanummer bijeengebracht zijn, spreken elk welhaast voor zich: nationale rechtspraak inzake mediation staat steeds centraal. De onderwerpen die bestreken worden door de Europese mediationrichtlijn 52/2008/EG, te weten '(vrijwilligheid bij) verwijzing naar mediation', 'vertrouwelijkheid', 'opschorting van termijnen' en 'uitvoerbaarheid' vormen veelal een rode draad die de bijdragen verbindt, al zijn er nationaal verschillende accenten. Gemeenschappelijk lijkt wel dat de onderwerpen 'opschorting van termijnen' en 'uitvoerbaarheid' - voor zover al apart geïmplementeerd - vooralsnog tot weinig jurisprudentie aanleiding lijken te hebben gegeven, al hebben diverse auteurs de afdwingbaarheid van eerder door partijen zelf overeengekomen mediationclausules onder de noemer 'uitvoerbaarheid' behandeld.

\section{De werking van contractuele mediationclausules}

Dit specifieke onderwerp blijkt meteen een dankbaar thema voor vergelijking, want uit de landenbijdragen komt een uiterst divers beeld naar voren. Franse en Duitse rechters achten zulke clausules in de regel juridisch bindend en zij zullen een partij die mediation wenst 'over te slaan' dus niet-ontvankelijk verklaren - zie de besproken uitspraken van het Cour de Cassation van 1 oktober 2014 en die van het Bundesgerichtshof (BGH) uit 2016. De Engelse rechtspraak kenmerkt zich door een (sinds Cable and Wireless v. IBM) geleidelijk terughoudender opstelling: zie de WAH case van het High Court uit 2012. En de Nederlandse rechtspraak vertegenwoordigt het meest extreme standpunt door zelfs zeer gedetailleerde clausules terzijde te schuiven, wanneer één der partijen niet meer geïnteresseerd zegt te zijn in mediation: zie bijvoorbeeld de uitspraak van de Rechtbank Overijssel uit 2014. Met name interessant is de Duitse uitspraak inzake het geschil tussen de Berlijnse balie en rechtsbijstandverzekeraar DEURAG over het door laatstgenoemde gehanteerde standaardbeding dat een verzekerde eerst mediation dient te beproeven alvorens advocaatkosten worden vergoed; anders dan de lagere rechtspraak zag het Bundesgerichtshof hier geen probleem in, ook niet nu DEURAG zich tevens de keuze van de mediator had voorbehouden. Alles gaat uiteindelijk terug op een ooit vrijwillig gesloten assurantieovereenkomst, aldus oordeelde het $B G H$.

\section{Verwijzing door de rechter en vrijwilligheid}

Aan dit onderscheid tussen de Frans/Duitse versus de Engels/Nederlandse rechtspraak lijkt een meer fundamenteel verschil van inzicht ten grondslag te liggen over het gewicht dat moet worden toegekend aan het consensuele karakter van mediation en aan de mogelijkheid dat een ooit door partijen zelf voorziene mediationpoging mogelijk alsnog tot resultaat zal leiden, wanneer de gezaghebbende rechter partijen aan hun voornemen houdt. 
Biedt de jurisprudentie inzake het eerstgenoemde onderwerp uit de mediationrichtlijn, te weten 'vrijwilligheid bij verwijzing' (door de rechter) hier wellicht meer duidelijkheid?

Ook hier blijkt een divers beeld te bestaan. Het ene uiterste wordt vertegenwoordigd door de Italiaanse rechter, of beter gezegd: de Italiaanse wetgever, die aspirant-procespartijen op veel gebieden verplicht eerst mediation te beproeven alvorens zij een beroep op de rechter mogen doen. Deze verplichting voor partijen, 'reloaded' na de Ciro di Donna affaire, is vanaf 2013 ook in die zin verbreed, dat de Italiaanse rechter in een reeds aanhangige zaak mediation mag bevelen. Opvallend is dan wel dat sancties op weigering eerst 'werkenderweg' in de rechtspraak worden ontwikkeld. Zoals de door Silvestri besproken uitspraken van de Rechtbank Rome laten zien, worden er inmiddels wel degelijk sancties opgelegd.

In het oog springt hier een parallel tussen Italië en Frankrijk. De Italiaanse wens tot dejuridisering (degiurisdizionalizzazione, zoals uitgedragen door o.a. de wet no. 162 uit 2014) weerklinkt in de Franse wet van 2016 Justice du XXIème siècle, kortweg de J21-wet, die immers evenzeer de belichaming vormt van een innige wens tot déjudiciariser, en zelfs een changement de culture, mede onder advocaten. ${ }^{6}$ Rechtspraak moet ultimum remedium worden, niet alleen om de samenleving vreedzamer te maken, maar ook (en met name) om de economische groei te bevorderen. Ook in Frankrijk is (al via een décret van 11 maart 2015) aan eisers/ verzoekers de plicht opgelegd in hun inleidend processtuk te preciseren wat gedaan is om tot een minnelijke regeling te komen; wanneer men hiervoor geen goede reden kan aanvoeren, dan mag de rechter voorstellen dat partijen alsnog conciliatie of mediation beproeven. ${ }^{7}$ Ook bij deze robuust ogende regeling lijkt echter, via de ruim omschreven 'goede redenen', de achterdeur bepaald niet op slot te zitten.

In Engeland en Nederland lijkt de situatie precies andersom te zijn. Hier wordt door de rechtspraak juist beleden dat medewerking van partijen aan een mediationpoging slechts op vrijwilligheid kan berusten: men vergelijke de uitspraak van het Court of Appeal inzake Halsey v. Milton Keynes NHS Trust en die van de Hoge Raad van 20 januari 2006. Maar tegelijkertijd lijkt er sprake van 'compulsion by the backdoor' (Clark); in Engeland fungeert het systeem van kostenveroordeling als zodanig (de High Court zaak PGF II SA v OMFS Co. biedt een fraai voorbeeld). In Nederland worden algemene rechtsbeginselen zoals 'goed werknemerschap' door de rechter gebruikt om daar achteraf een verplichting tot medewerking aan mediation uit te destilleren. En ook dan zijn de sancties concreet in de portemonnee voelbaar.

Zien we aldus in de meer zuidelijke Europese landen vooral het 'grote (politieke) gebaar', gepaard gaande met veel wetgeving, waar echter nogal wat losse eindjes

6 De Franse overheid lijkt hier iets steviger in de schoenen te staan dan de Italiaanse, die, zoals Silvestri in haar bijdrage beschrijft, de heftig protesterende balie heeft geapaiseerd door verplichte rechtsbijstand door een advocaat tijdens mediation voor te schrijven en advocaten een 'automatische' kwalificatie als mediator mee te geven.

7 Meer over het onderscheid tussen mediation en conciliatie infra, in de laatste paragraaf van dit redactioneel. 
aan blijven hangen op uitvoeringsniveau? En contrasteert daarmee in NoordwestEuropa een met de mond beleden respect voor autonomie, welke evenwel op uitvoeringsniveau flink wordt ingeperkt, althans wanneer beheersing van de publieke uitgaven in het geding komt? Het klinkt clichématig, maar toch.

Waar staat Duitsland in deze tweedeling? Hier huldigt de rechtspraak al van vóór de inwerkingtreding van de Mediationsgesetz (2012), dat medewerking aan mediation op vrijwilligheid dient te berusten. Intrigerend is het recente evaluatierapport inzake de effectiviteit van deze wet en de ontwikkeling van mediation in Duitsland. ${ }^{8}$ In dit rapport wordt geconstateerd dat de ontwikkeling van het aantal mediations stagneert (met zo'n 7400 mediations in 2016) en dat het potentieel van mediation zo niet volledig benut wordt. Maar oplossingen worden hier niet gezocht in de verplichtstelling van mediation - die optie wordt niet eens genoemd - maar in zaken als betere financiële ondersteuning van (zwakkere) partijen in mediations en in duidelijke beroepskwalificaties voor mediators. De auteurs van het rapport betwijfelen echter of dat soort maatregelen iets zal veranderen aan de bereidheid om mediation te beproeven.

\section{Vertrouwelijkheid}

De vertrouwelijkheid van mediation vormt wellicht een minder beladen onderwerp, waar niettemin behoorlijk wat jurisprudentie over bestaat, met name in Engeland en Nederland. ${ }^{9}$ Noch in Engeland noch in Nederland kan men veilig aannemen dat de contractuele geheimhoudingsplichten aangegaan door de mediator en door ieder der partijen stand zullen houden wanneer een rechter zich geroepen voelt zijn plicht tot materiële waarheidsvinding uit te oefenen. Wel komen uit de besproken rechtspraak nuanceverschillen naar voren. Dit blijkt bijvoorbeeld wanneer één der partijen achteraf in de rechtszaal een beroep doet op wilsgebreken. De Engelse rechter lijkt dan meer bereid de contractuele geheimhoudingsafspraken te negeren dan de Nederlandse rechter: men vergelijke bijvoorbeeld de uitspraak van het High Court inzake Farm Assist Ltd (no. 2) uit 2009 met die van het Hof Amsterdam van 18 december 2003.

In Frankrijk geldt al sinds een uitspraak van het Tribunal de Grande Instance van Parijs uit 1998 dat de contractuele geheimhoudingsplichten te allen tijde gerespecteerd dienen te worden. Het is aan de rechter om een bewijsaanbod dat hierop inbreuk maakt te weigeren. Ook in Duitsland lijken de contractuele geheimhoudingsplichten onomstreden, getuige bijvoorbeeld de besproken uitspraak uit 2008 van het Verwaltungsgericht Düsseldorf. De uitspraak uit 2007 van de speciale instantie voor advocaten(tuchtzaken), het Anwaltsgericht, maakt inmiddels duidelijk wat het nut is van een contractuele geheimhoudingsplicht; waar deze zoals in casu niet is overeengekomen, beperkt de wettelijke verplichting van de advocaat

8 K. Masser, B. Engewald, L. Scharpf and J.Ziekow, Evaluierung des Mediationsgesetzes; Rechtstatsächliche Untersuchung im Auftrag des Bundesministeriums der Justiz und für Verbraucherschutz, Speyer, 14 June 2017.

9 In beide landen is de EU Mediationrichtlijn strikt geïmplementeerd, dat wil zeggen beperkt tot grensoverschrijdende geschillen. 
zich voor wat betreft geheimhouding slechts tot diens eigen cliënt, niet tevens tot de tegenpartij!

\section{Mediators, conciliateurs en Güterichter}

Er zijn nog vele andere interessante (rechts)vragen die in de hiernavolgende bijdragen de revue passeren. Zo is er het onderwerp gefinancierde rechtshulp en mediation, en passeren kwesties rond onafhankelijkheid en onpartijdigheid de revue. Meer organisatorisch van aard is bijvoorbeeld het onderscheid tussen 'conciliatie' en 'mediation', dat zowel Frankrijk als Italië hanteren. Conciliatie lijkt historisch vooral te verwijzen naar de schikkingstaak als onderdeel van de mission van de rechter. Frankrijk kent al geruime tijd de conciliateurs de justice, vrijwilligers aan wie die schikkingstaak als het ware is gedelegeerd, die meer evaluatief mogen werken en die jaarlijks verslag uitbrengen aan de rechterlijke instantie in hun ressort. Hiernaast opereren meer recent de médiateurs, die net als externe mediators in Nederland onafhankelijk zijn, voor hun diensten een honorarium berekenen en vooral faciliterend te werk gaan. ${ }^{10}$ In Duitsland kent men ook de traditionele schikkingstaak van rechters, maar heeft men daarnaast een nieuwe variant ingevoerd, te weten de rechter die is getraind in mediation en los van de rechter die de zaak behandelt als mediator optreedt (gerichtsinterne Mediation; dergelijke rechters worden nu als Güterichter aangeduid). Deze variant is (nog) onbekend in Engeland en Nederland; niet denkbeeldig is dat de vrees voor extra benodigde budgetten voor een dergelijke variant hieraan debet is.

Vrijwel alle bijdragen zijn in de Engelse taal geschreven, met uitzondering van de Franse. ${ }^{11}$ De redactie hoopt dat op deze manier niet alleen $u$, als TMD-lezer uit Vlaanderen of Nederland, maar ook lezers uit de andere betrokken lidstaten kennis zullen kunnen nemen van de ontwikkelingen in de rechtspraak bij 'de buren'. ${ }^{12}$ De discussie over de overeenkomsten en - vooral - de verschillen in de nationale rechtspraak binnen Europa zal ongetwijfeld in de nabije toekomst, al dan niet in dit tijdschrift, een vervolg krijgen. Affaire à suivre.

10 Hierover meer uitgebreid: M. Juston, La Mediation et la Conciliation: sont elles interchangeables?, conference tenue le 21 mai 2017.

11 Helaas zagen de uitgevers geen mogelijkheid om de Franse bijdrage integraal te laten vertalen.

12 Hoewel men uiteindelijk door vergelijking ook de rechtspraak in eigen land (weer) beter leert kennen. Voor de redactie was het goed te constateren, dat de advocaten-generaal in hun conclusies bij de hier besproken uitspraken van de Hoge Raad steevast naar artikelen gepubliceerd in TMD verwezen. Een fraaie blijk van erkenning! 